\title{
NEO OPEN INNOVATION IN THE Digital ECONOMY: HARNESSING SOFT INNOVATION RESOURCES
}

\author{
Yuji Tou ${ }^{1}$, Chihiro Watanabe ${ }^{2,3}$, Kuniko Moriya ${ }^{4,5}$, Pekka Neittaanmaki ${ }^{6}$ \\ ${ }^{1}$ Dept. of Ind. Engineering \&Magm, Tokyo Institute of Technology, Tokyo, Japan

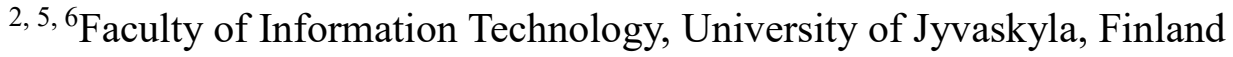 \\ ${ }^{3}$ International Institute for Applied Systems Analysis (IIASA), Austria \\ ${ }^{4}$ Research and Statistics Department, Bank of Japan, Tokyo, Japan \\ ${ }^{6}$ Faculty of Information Technology, University of Jyvaskyla, Finland
}

\begin{abstract}
Successive increases in $R \& D$ that creates new functionality are essential for global competitiveness. However, unexpectedly, as a consequence of the two-faced nature of information and communication technology (ICT), excessive $R \& D$ results in a marginal productivity decline leading to a decrease in digital value creation. In order to overcome such a dilemma, global ICT firms have been endeavoring to transform themselves into disruptive business model. Neo open innovation that harnesses soft innovation resources may be a solution to this critical question. On the basis of an empirical analysis focusing on forefront endeavors to this dilemma by global ICT firms, this paper attempted to demonstrate the above hypothetical view. Noteworthy findings suggestive to transforming the traditional business model into disruptive innovation that satisfies people's demand corresponding to their shift in preferences in the digital economy is thus provided. In addition, a new concept for $R \& D$ resources in the digital economy is postulated.
\end{abstract}

\section{KEYWORDS}

Digital economy, soft innovation resources, neo-open innovation, disruptive business model, transformation

\section{INTRODUCTION}

The dramatic advancement of the Internet has generated the digital economy, which has changed the way of conducting business and daily lives [1]. The further progression of digitalized innovation over the last two decades, such as cloud, mobile services, and artificial intelligence, has augmented this change significantly and has provided us with extraordinary services and welfare never anticipated before [2].

This progression has revealed a two-faced nature of information and communication technology (ICT): simultaneous dissemination of ICT cross over the world regardless of economic level, and bipolarization of productivity depending on the stage of advancement [3].

While highly digitalized ICT such as the Internet and smart phones are, contrary to traditional technologies, disseminate with similar speed regardless of the income level, it leads to 
International Journal of Managing Information Technology (IJMIT) Vol.10, No.4, November 2018

bipolarization of productivity between high $\mathrm{R} \& \mathrm{D}$-intensive firms and low $\mathrm{R} \& \mathrm{D}$-intensive firms in the extremely competitive environment [3].

High R\&D-intensive global ICT firms have been confronting a dilemma between R\&D expansion and productivity decline and have been urged to transforming themselves into disruptive business model [3]. Such transformation efforts in global ICT leaders inevitably reconstruct R\&D structure in the world R\&D leaders.

Fig. 1 demonstrates trend in R\&D expenditure in world top 1000 firms by sectors over the period of 2005-2019. Looking at Fig. 1 we note a clear contrast among ICT sectors. While computing \& electronics initiated by such global ICT leaders as Samsung and Intel have been maintaining the highest expenditure position, their level has changed to slightly decrease from 2013. Contrary to such decrease, software and Internet initiated by Google (Alphabet), Microsoft, Huawei and Apple have shown a conspicuous increase particularly from the second decade of this century and are expected to exceed the level of computer \& electronics in very near future.



Figure 1. Trend in R\&D expenditure in world top 1000 firms by sectors (2005 - 2019).

2018 and 2019 are estimated values.

Original source: [4].

Inspired by this striking trend, Fig. 2 demonstrates world top 25 R\&D leaders by their R\&D expenditure in 2017. Fig. 2 demonstrates the above R\&D reconstruction trend. Contrary to notable R\&D growth rate in software and Internet leaders in 2017 as $40.4 \%$ (Amazon), 12.7\% (Google), 8.8\% (Microsoft), 28.5\% (Huawei) and 24.5\% (Apple), growth rate in computer \& electronics has shown extremely lower as $-3.2 \%$ (Samsung) and 5.0\% (Intel). Noteworthy is Amazon's conspicuous jump. It invested 22.6 billion US\$ R\&D in 2017 and jumped up to the world top exceeding rivals of global ICT leaders. It is only in the past few years that Amazon's spending has ranked among the potential global leaders in R\&D. Its R\&D spending has doubled since 2015, quintupled since 2012 and is up tenfold since 2011. 
International Journal of Managing Information Technology (IJMIT) Vol.10, No.4, November 2018

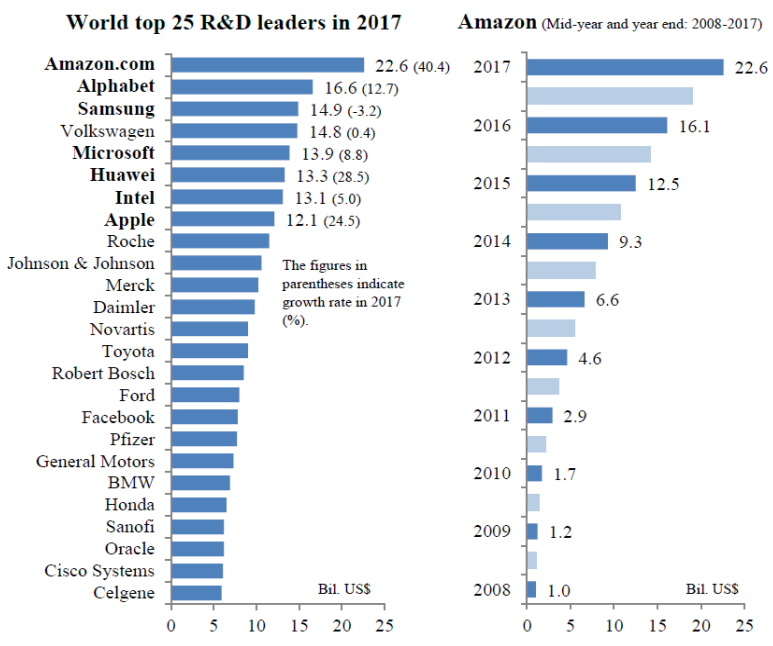

Figure 2. Amazon's conspicuous jump into the world R\&D leader in 2017.

Original sources: [4] [5].

Given the dilemma between R\&D expansion and productivity decline that global ICT leaders have been confronting and their endeavor to transforming themselves into disruptive business model, above contrast between two leading ICT sectors and conspicuous increase in software and Internet leaders despite such dilemma suggest the emergence of neo open innovation that harnesses new external innovation resources that does not accelerate productivity decline.

To date, while many studies demonstrated the significant role of open innovation (e.g., [6][7]) and also of harnessing the vigor of emerging economies (e.g., [8]), none has identified practical solutions against the above dilemma in the context of open innovation.

Following the preceding analyses, on the basis of an empirical analysis focusing on the development trajectories of 500 global ICT firms over the period 2005-2016, this paper attempts to shed light on the unknown dynamism with respect to neo open innovation that harnesses the vigor of soft innovation resources amidst mega-competition in the digital economy.

Section 2 over reviews dilemma between R\&D increase and productivity decline. Neo open innovation in the digital economy against such dilemma is discussed in Section 3. Section 4 assesses the soft innovation resources which play a central role in neo open innovation. Section 5 summarizes the noteworthy findings, policy suggestions, and future research.

\section{Dilemma Between R\&D Increase And Productivity Decline}

\subsection{Two-FACED NATURE OF ICT}

\subsubsection{Simultaneous Dissemination}

The dramatic advancement of the Internet and the further progression of digitized innovation over the last two decades, such as cloud services, mobile services, and artificial intelligence amidst the advancement of the digital economy have augmented the permeation of the Internet into not only broad ICT but also all production factors leading to an IoT society.

In this permeation process digitalized innovation mutually stimulates each other leading to coevolutionary dynamics and creates new social ecosystem [9]. 
Figs. 3 and 4 demonstrate correlation between GDP per capita and Internet use ratio and smartphone ownership ratio in 40 countries (11 countries in advanced economies (AE) and 29 countries in emerging and developing economies (EDE)) in 2015, respectively.

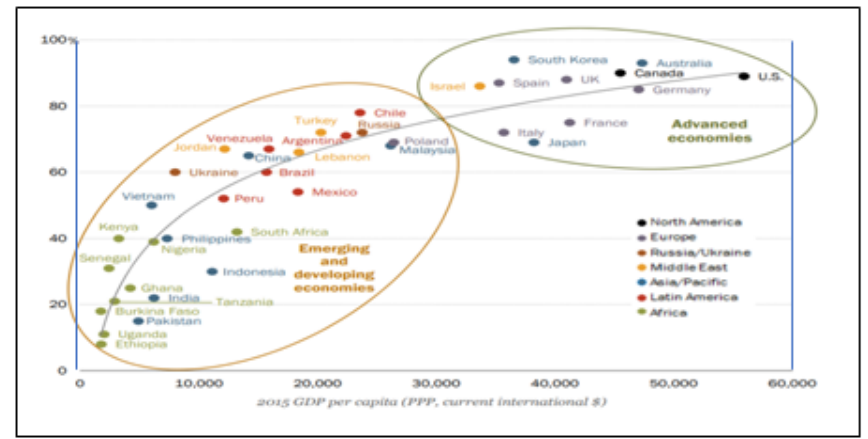

Figure 3. Correlation between GDP per capita and Internet usage ratio in 40 countries (2015). Source: [10].

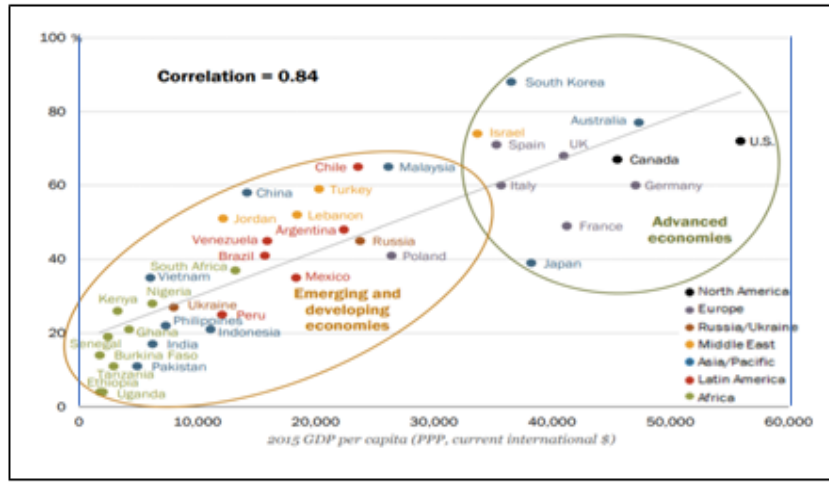

Figure 4. Correlation between GDP per capita and smartphone ownership ratio in 40 countries (2015).

Source: [10].

Figs. 3 and 4 demonstrate that ICT permeates simultaneously into 40 countries regardless of economic development stage. Previously, delay in economic development was fundamental impediments in emerging and developing economies resulting in a vicious cycle between economic development and technological advancement. However, Figs. 3 and 4 demonstrate that countries in emerging and developing economies enjoy the Internet and smartphone notwithstanding their low level of economic development.

Fig. 5 demonstrates that, contrary to traditional technology, the discrepancy of speed of dissemination of advanced ICT such as the Internet and mobile phones between high-income countries and low-income countries has dramatically decreased. 
International Journal of Managing Information Technology (IJMIT) Vol.10, No.4, November 2018

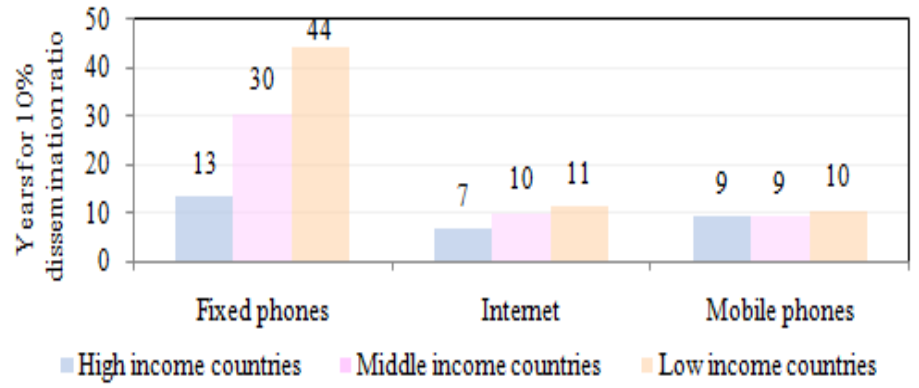

Figure 5. Years for $10 \%$ dissemination ratio on fixed phones, Internet and mobile phones by income level. Source: [11].

Such worldwide simultaneous dissemination creates ICT-driven new social ecosystem [12]. In this dissemination process digitalized innovation mutually stimulates each other leading to coevolutionary dynamics and creates new social ecosystem. Figs. 6 and Table 1 demonstrate strong correlation between Internet use and smartphone ownership in 40 countries regardless of economic level. Such strong correlation stimulates co-evolutionary development of ICT advancement leading to creating new social ecosystem.

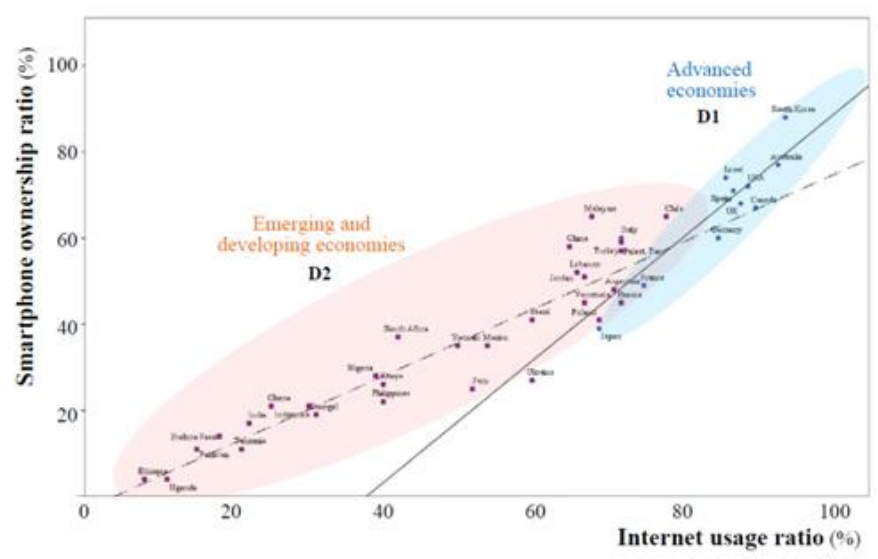

Figure 6. Correlation between Internet usage and smart phone ownership in 40 countries (2015).

Table 1. Correlation between Internet usage and smart phone ownership in 40 countries (2015).

$\ln \boldsymbol{S P}=-0.941+1.153 D_{1} \ln \boldsymbol{I D}+1.147 \ln D_{2} \boldsymbol{I D} \quad$ adj. $R^{2} 0.933$

$$
(-4.31)(22.66)
$$

$S P$ : Smartphone ownership ratio; $I D$ : Internet usage ratio; $D$ : Dummy variables $\left(D_{I}: A E=1, E D E\right.$ $\left.=0 ; D_{2}: A E=0, E D E=1\right)$.

The figures in parenthesis indicate t-statistics: All are significant at the $1 \%$ level.

This simultaneous dissemination cross over techno-economy can be one of the unique highlighting feature of the digital innovation [12] [9]. 


\subsubsection{Bipolarization}

Contrary to the above simultaneous feature, ICT incorporates contrasting nature, bipolarization derived from its two-faced nature with respect to prices formation. While advancement of ICT generally contributes to enhanced prices of technology by new functionality development, the dramatic advancement of the Internet reacts to decreased prices of technology due to its nature of freebies, easy and free replication and mass standardization.

Fig. 7 illustrates this dynamism which demonstrates bipolarization between price increase and decrease depending on the ICT advancement

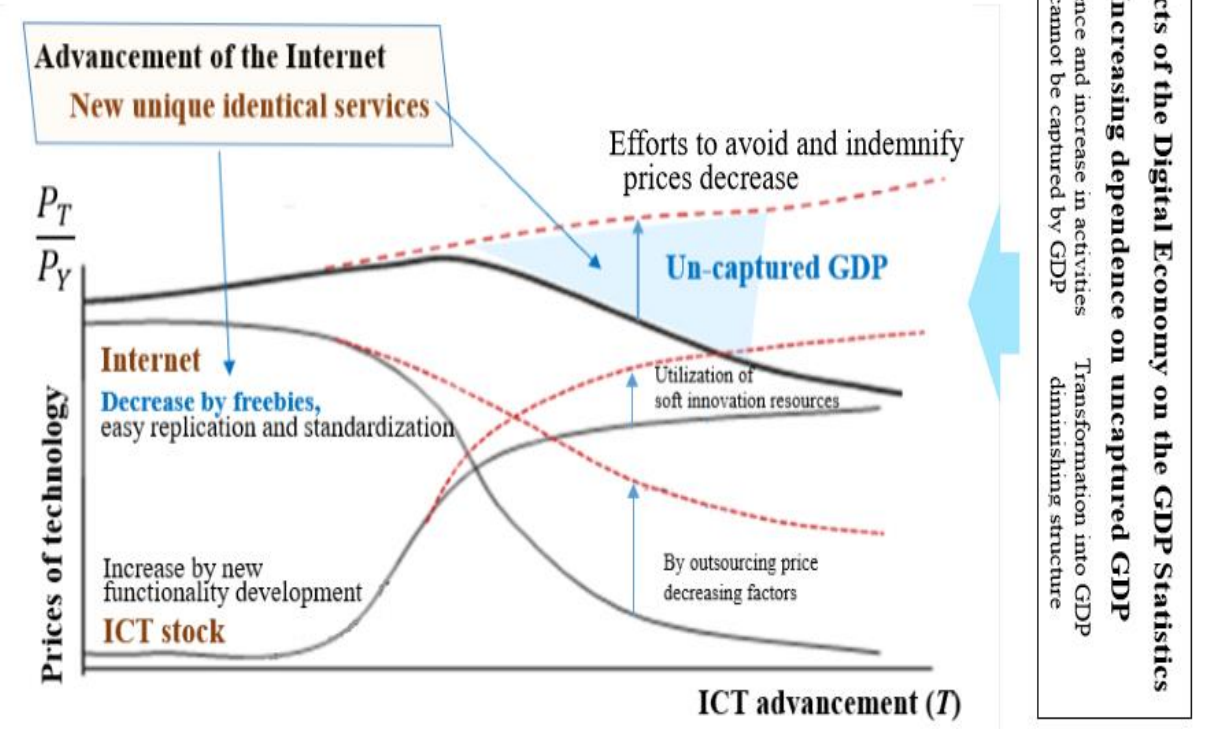

Figure 7. Dynamism of ICT price decrease as a consequence of its two-faced nature.

Consequently, such bipolarization has become inevitable in the competitive game in global ICT firms. Provided that these firms seek to profit maximum in the competitiveness market, prices decrease as a consequence of excessive ICT advancement results in their marginal productivity of ICT decline. Fig. 8 demonstrates such phenomena in 500 global ICT firms in 2005 and 2016. Fig. 8 demonstrates explicit bi-polarization between high R\&D-intensive firms (HRIFs) and remaining low R\&D-intensive firms (LRIFs). HRIFs have fallen into a vicious cycle between R\&D expenditure centered by ICT and its marginal productivity, as the former increase results in declining the latter. On the contrary, LRIFs have maintained a virtuous cycle, as R\&D increase leads to marginal productivity increase.

This bipolarization nature can be another unique feature of ICT. Thus, ICT incorporates two-faced nature: simultaneous permeation and bipolarization. Bipolarization can also be attributed to twofaced nature with respect to prices formation. 
International Journal of Managing Information Technology (IJMIT) Vol.10, No.4, November 2018

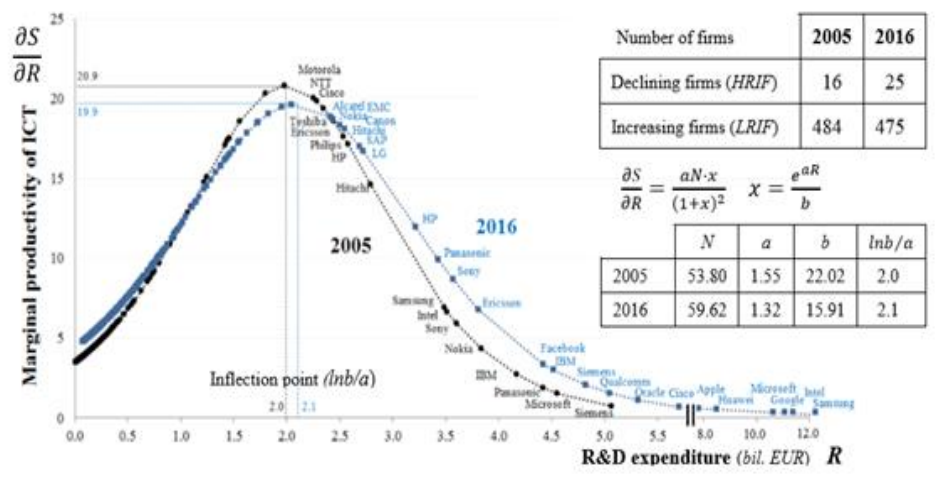

Figure 8. Comparison of marginal productivity of ICT in 500 global ICT firms (2005 and 2016).

Original sources [13] [14].

\subsection{DILEMMA IN HIGH R\&D-INTENSIVE FIRMS}

Global ICT firms have been endeavoring to increase their digital values centered on sales $(S)$ [14]. Growth rate of sales $(\Delta S / S)$ largely depends on ICT $(T)$ advancement rather on traditional production factors $(X)$ as labor $(L)$ and capital $(K)$. ICT contribution to sales growth can be approximated by product of marginal productivity of ICT $(\partial S / \partial T$ ) and R\&D intensity (ratio of R\&D centered on ICT and sales: $R / S$ ) as depicted by equation (1).

$$
\frac{\Delta S}{S}=\sum \frac{\partial S}{\partial X} \cdot \frac{X}{S}+\frac{\partial S}{\partial T} \cdot \frac{R}{S}
$$

Global ICT firms endeavor to grow sales by leveraging ICT's contribution to this growth which consists of increase in marginal productivity of ICT $(M P)$ and R\&D intensity $(R)$. Product of both factors $(M P \times R)$ represents the contribution of ICT to sales growth rate as depicted in equation (1). Fig. 9 illustrates this strategy by stages of global position by R\&D level.

This strategy can be attained by constructing a virtuous cycle between $M P$ and $R$ ( $R$ increase leads to $M P$ increase which in turn induces further $R$ increase) as far as global ICT firms remain LRIFs (stage A in Fig. 9). However, once they move up to HRIFs (stage B), they fall into a vicious cycle ( $R$ increase result in declining $M P$ (stage $\mathrm{C})$ ). In this pitfall, $M P$ recovery can be attained by reducing $R$ (move back to $\mathrm{A}$ ) which results in diminishing sales growth target.

In order to attain the sales growth target essential for global ICT firms for their survival, HRIFs should find disruptive innovation solution by overcoming this dilemma. This solution can be found through

(i) Incorporation of the vigor of LRIFs that enjoy a virtuous cycle between $R$ and $M P$, and/or,

(ii) Harnessing the vigor of external innovation resources that do not accelerate a vicious cycle.

The former option can be expected by harnessing the vigor of emerging and developing countries (they remain stage A) that also enjoy the benefit of digital innovation simultaneously while the latter option can be expected by means of neo open innovation that harnesses the vigor of soft innovation resources (which is external to $R$ ) corresponding to the digital economy. 


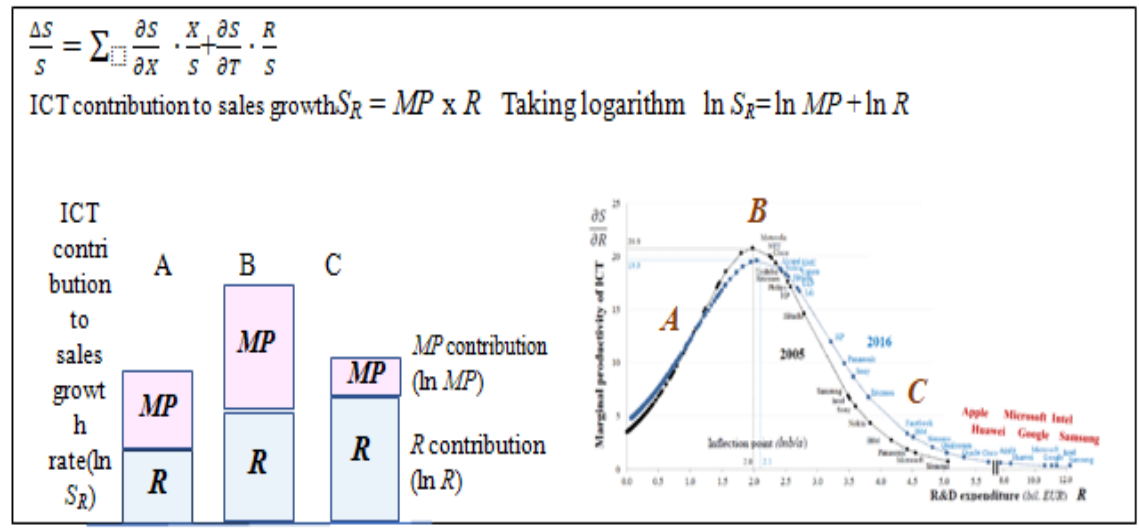

Figure 9. Illustration of ICT-driven competitiveness strategy in global ICT firms.

Fig. 10 compares development trajectory of world ICT leaders, Finland and Singapore over the period of 2013-2016 by GDP growth rate and dependence on profits from abroad. Fig. 10 demonstrates that recent reversal trend on GDP growth between two leaders can partially be attributed to dependence on profits from abroad. Together with effective utilization of soft innovation resources (option (ii)), Finland's recent economic resurgence [15] [16] can be attributed to increasing dependence on these profits as GNI/GDP ratio is increasing with higher than 1 level $($ GNI $(\mathrm{GNP})-\mathrm{GDP}=$ Income balance + Balance derived from the terms of trade $>0)$ while opposite in Singapore which suffers decreasing trends both in GDP growth rate and profits from abroad (GNI/GDP < 1). This can be as a consequence of the difference of the dependence on option (i) above and inspires us co-evolution between resilience of high-level of welfare/happiness and sustainable growth which previously considered generally trade-off.

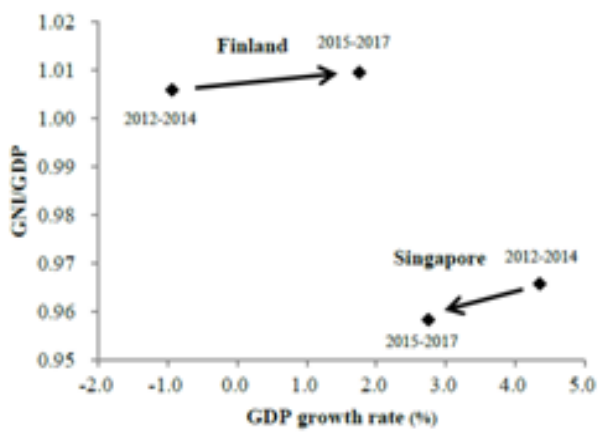

\begin{tabular}{|c|c|c|c|c|c|}
\hline & & GNIGDP & GDP prowth nate $(\mathrm{S})$ & ICT ranking & Haspinest rankint \\
\hline \multirow{2}{*}{ Finland } & 2012-2014 nespen & 1.006 & .0 .94 & 2 & 6 \\
\hline & 2015-2017 newp & 1.010 & 1.76 & 1 & 1 \\
\hline \multirow{2}{*}{ Singapore } & 2012-2014 meapp & 0.966 & 4.36 & 1 & 24 \\
\hline & 2015.2017 ment & 0.958 & 2.75 & 2 & 34 \\
\hline
\end{tabular}

Figure 10. Development trajectories of world ICT leaders (2013-2016).

Effects of the consequence of the option (ii) is discussed in the next Section. 
International Journal of Managing Information Technology (IJMIT) Vol.10, No.4, November 2018

\section{Neo Open InNOVATion in The Digital ECONOMY}

\subsection{Endeavor Against Productivity Decline}

Confronting the above dilemma, HRIFs have been endeavoring to transform into a new disruptive business model that creates new functionality that satisfies people's preferences in the digital economy by minimum expenditures.

ICT incorporates explicit network externalities function to alter the correlation between innovations and institutional systems. This altered correlation creates new features of the innovation leading to an exponential increase [17]. Schelling [18] portrayed an array of logistically developing and diffusing social mechanisms stimulated by these interactions. These postulates convince us a logistic increase of ICT in its development and diffusion process.

With this understanding together with preceding demonstration that digital value of global ICT firms is represented by sales $(S)$ which are governed by their ICT stock (T) [13] [14] their development trajectory can be depicted as follows:

$S=F(X, T)=F(X(T)) \approx F(T)$

where $X$ : production factors other than $T$.

In long run, $T$ can be treated proportional to R\&D investment $(R)$ [19].

Thus, increasing trajectory of $S$ in global ICT firms can be depicted by the following $R$-driven logistic growth function:

$$
\frac{d S}{d R}=a S\left(1-\frac{S}{N}\right)
$$

Given the global ICT firms, equation (3) can be approximated as follows [19]:

$$
\frac{d S}{d R}=a S\left(1-\frac{S}{N}\right) \approx \frac{\partial S}{\partial R}
$$

Equation (3) is developed to the following simple logistic growth ( $S L G$ ) function which incorporates special advantage in assessing the state and prospect of productivity and development trajectory objectively:

$$
S_{S}(R)=\frac{N}{1+b e^{-a R}}
$$

Where $b$ : coefficient indicating the initial state of the diffusion.

While the level of carrying capacity $(N)$ is assumed constant through the development process in $S L G$, in particular innovations, the correlation of the interaction between innovation and institutions 
International Journal of Managing Information Technology (IJMIT) Vol.10, No.4, November 2018

display a systematic change in the process of growth and maturity. This leads to the creation of a new carrying capacity in the process of its development as follows:

$$
\frac{d S(R)}{d R}=a S(R)\left(1-\frac{S(R)}{N(R)}\right)
$$

This leads to the following logistic growth within a dynamic carrying capacity ( $L G D C C$ ) function, which demonstrates the level of carrying capacity enhances as development proceeds:

$$
S(R)=\frac{N_{k}}{1+b e^{-a R}+\frac{b_{k}}{1-\frac{a_{k}}{a} e^{-a_{k} R}}} .
$$

where $N_{k}$ : ultimate carrying capacity, and $a_{k}$ and $b_{k}$ : coefficients similar to $a$ and $b$.

Equation (7) demonstrates that the third term of the denomination governs the dynamic carrying capacity and, without this term, results in $S L G$ with a constant carrying capacity.

From equation (6), dynamic carrying capacity can be expressed as follows:

$$
N(R)=S(R)\left(\frac{1}{1-\frac{1}{a} \cdot \frac{d S(R)}{d R} / S(R)}\right)
$$

This demonstrates that $N(R)$ increases together with that of $\mathrm{S}(\mathrm{R})$ and its $\mathrm{R} \& \mathrm{D}$-driven growth rate. This implies that the $L G D C C$ function demonstrates functionality development in the context of the self-propagating behavior (Watanabe et al., 2004: Watanabe et al., 2009) and $N(R)$ represents the magnitude of the self-propagating function.

Since the potential of functionality development can be traced by the ratio of development state and its upper limit (carrying capacity) [20], functionality development in the $L G D C C$ function can be depicted from equation (8) as follows:

This demonstrates that $N(R)$ increases together with that of $S(R)$ and its R\&D-driven growth rate. This implies that the $L G D C C$ function demonstrates functionality development in the context of the self-propagating behavior [17] [20] and $N(R)$ represents the magnitude of the self-propagating function

Since the potential of functionality development can be traced by the ratio of development state and its upper limit (carrying capacity) [20], functionality development in the LGDCC function can be depicted from equation (8) as follows:

$$
\begin{aligned}
& \text { Functionality } \\
& \text { development }
\end{aligned}=F D=\frac{N(R)}{S(R)}=\frac{1}{1-\frac{1}{a} \cdot \frac{d S(R)}{d R} / S(R)}
$$


This equation demonstrates that self-propagating function represented by $N(R)$ induces functionality development that leads to supra-functionality.

With the understanding that this self-propagating function can be attributed to its adaptability to ICT-driven logistic growth within a dynamic carrying capacity ( $L G D C C$ ) function that increases functionality as it grows rather than a simple logistic growth $(S L G)$ function that fades out functionality as it grows [17].Table 1 compares $S L G$ and $L G D C C$ functions of 500 global ICT firms in 2005 and 2016 which demonstrates that the $L G D C C$ is statistically more significant than the $S L G$.

Table 1. Comparison of development trajectory of the 500 global ICT firms in 2005 and 2016.

\begin{tabular}{ccccccc} 
SLG & $S=\frac{N}{1+b e^{-a \ell R}}+c D$ \\
\hline \multirow{2}{*}{2005} & $\begin{array}{c}53.80 \\
(21.18)\end{array}$ & $\begin{array}{c}1.55 \\
(16.96)\end{array}$ & $\begin{array}{c}22.02 \\
(29.44)\end{array}$ & $\begin{array}{c}42.63 \\
(18.13)\end{array}$ & 0.734 & Dell \\
\hline \multirow{2}{*}{2016} & $\begin{array}{c}59.62 \\
(17.39)\end{array}$ & $\begin{array}{c}1.32 \\
(10.98)\end{array}$ & $\begin{array}{c}15.91 \\
(21.87)\end{array}$ & $\begin{array}{c}99.09 \\
(29.74)\end{array}$ & 0.784 & Samsung,Apple, Hon Hai \\
\hline
\end{tabular}

$$
L G D C C \quad S(R)=\frac{N_{k}}{1+b e^{-a f}+\frac{b_{k}}{1-\frac{a_{k}}{a} k^{-} k_{k}^{g}}}
$$

\begin{tabular}{ccccccc}
\hline & $N_{k}$ & $a$ & $b$ & $a_{k}$ & $b_{k}$ & adj. $R^{2}$ \\
\hline \multirow{2}{*}{2005} & 75.28 & 1.27 & 26.65 & 0.35 & 0.34 & 0.999 \\
& $(30.37)$ & $(177.19)$ & $(25.42)$ & $(2.50)$ & $(6.71)$ & \\
\hline \multirow{2}{*}{$\mathbf{2 0 1 6}$} & 102.23 & 0.77 & 15.84 & 0.43 & 1.32 & \multirow{2}{*}{0.999} \\
& $(178.83)$ & $(26.13)$ & $(9.72)$ & $(7.06)$ & $(2.53)$ & \\
\hline
\end{tabular}

The figures in parentheses indicate t-statistics: All are significant at the $1 \%$ level.

Original source: [13].

The magnitude of the self-propagation function can be estimated by the ratio of $N(R)$ (dynamic carrying capacity of $L G D C C$ that leads development trajectory after incorporating the selfpropagating function) and $S_{S}(R)$ (development trajectory estimated by $S L G$ that demonstrates development level when no self-propagating function incorporates) [21].

Based on these analyses, Fig. 11 illustrates dynamism of HRIFs in 2016 in transforming productivity decline into supra-functionality beyond economic value that satisfies people's preferences in the digital economy. 
International Journal of Managing Information Technology (IJMIT) Vol.10, No.4, November 2018

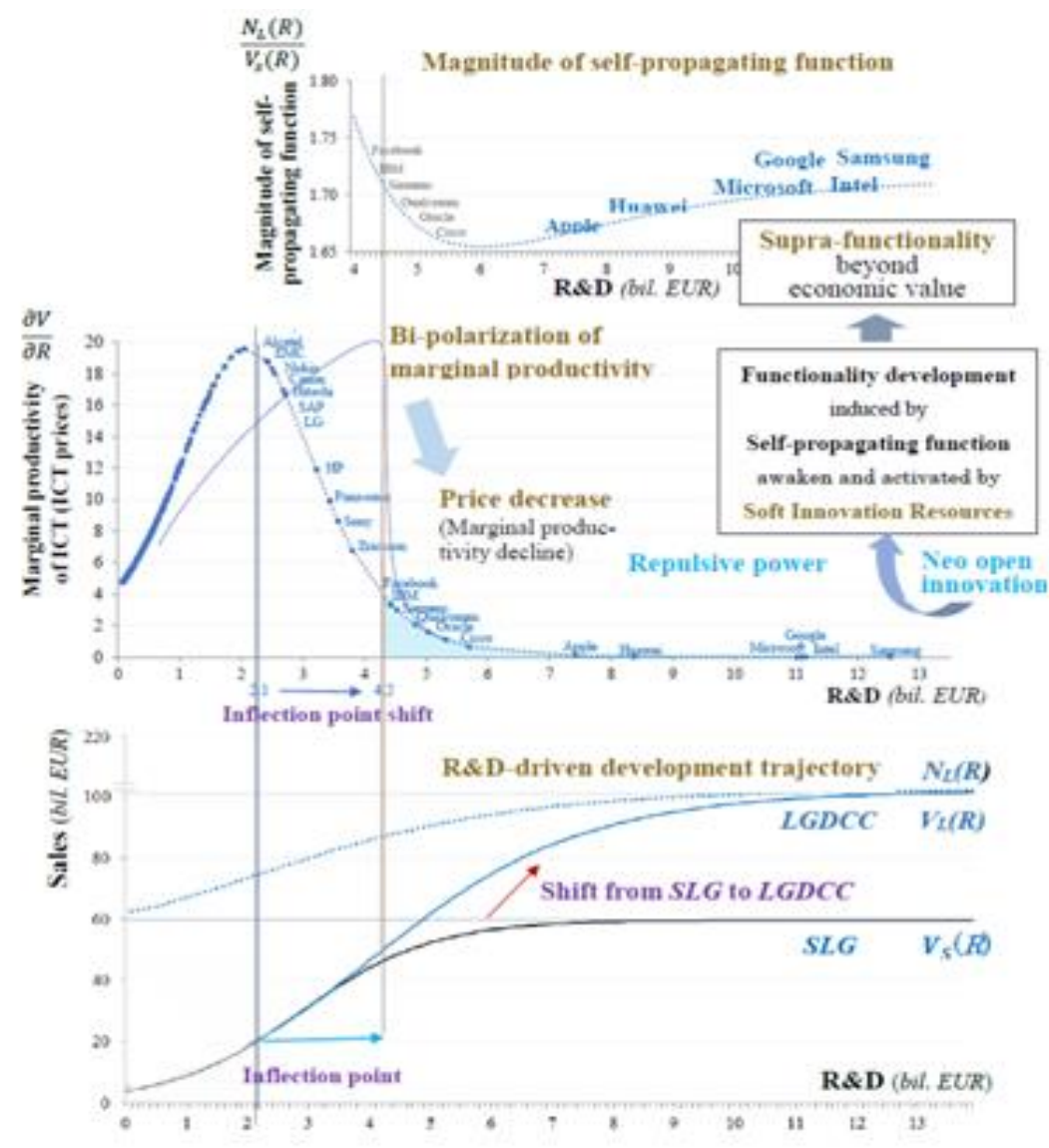

Figure 11. Dynamism in transforming productivity decline into supra-functionality beyond economic value in HRIFs (2016).

$V_{S}(R)$ : Digital value in $S L G$ (equivalent to $S_{S}(R)$ ), $V_{L}(R)$ : Digital value in $L G D C C$ (equivalent to $S(R)), N_{L}(R)$ : Dynamic carrying capacity in LGDCC (equivalent to $N(R)$ ).

Bottom of Fig. 11 demonstrates R\&D-driven development trajectory of 500 global ICT firms in 2016. This trajectory shifted from $S L G$ to $L G D C C$ by activating latent self-propagating function as R\&D investment increases. This can be a countermeasure against marginal productivity of ICT decline once exceeding certain R\&D investment level (inflection level) as demonstrated in the middle of Fig. 11.

This inflection level in $L G D C C$ is much higher than that of in $S L G$ without self-propagating function which implies global ICT firms can avoid productivity decline to some extent by attempting to increase self-propagating function as illustrated in the middle left of Fig. 11.

However, there exists certain limit to maintain productivity increase just by such effort. Thus, excessive dependence on R\&D (proportional to ICT that incorporates a two-faced nature of prices formation) necessitates effective utilization of external resources (the vigor of LRIFs that enjoy a virtuous cycle between $R$ and $M P$, and/or external resources that do not accelerate a vicious cycle) for compensating productivity decline as reviewed in Section 2. 
Fig. 11 shows that, in repulsion to marginal productivity of ICT decline, self-propagating function increases in extremely high R\&D-intensive global ICT firms such as Samsung, Intel, Google, Microsoft, Huawei and Apple as demonstrated in the top right of Fig. 10 with their high level of magnitude of self-propagating function. Thereby these firms correspond to people's preferences shift to supra-functionality beyond economic value [23].

\subsection{NEO OPEN INNOVATION}

\subsubsection{Disruptive Business Model Initiated by Global ICT Leaders}

The above analyses demonstrate the new disruptive business model initiated by global ICT leaders in increasing functionality development by exploring and utilizing external resources that arouse and activate latent self-propagating function indigenous to ICT. Activated self-propagating function induces functionality development leading to supra-functionality beyond economic value corresponding to people's preferences shift. This shift in turn induces further advancement of the Internet and leverages co-evolutionary advancement of innovation in the digital economy as illustrated in Fig. 12.

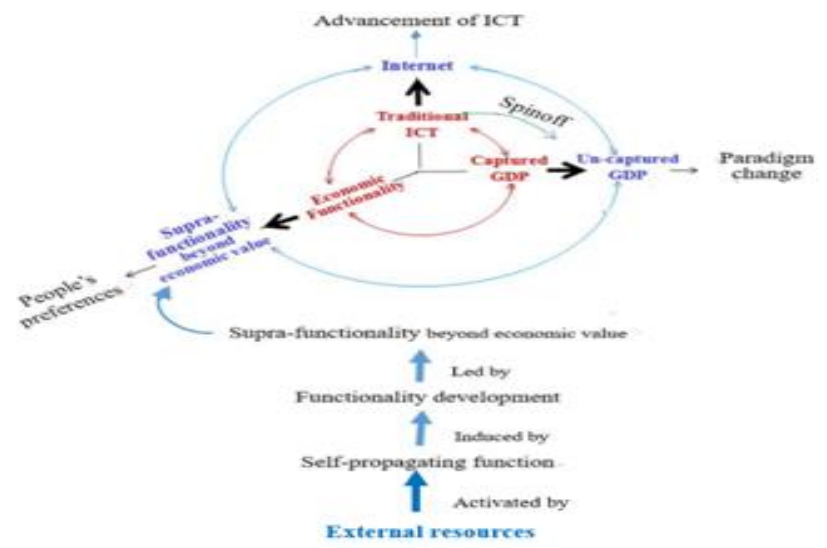

Figure 12. Disruptive business model initiated by global ICT leaders

As postulated in Section 2 these external resources could be incorporation of the vigor of LRIFs that enjoy a virtuous cycle between $R$ and $M P$, and/or, external innovation resources that do not accelerate a vicious cycle.

Harnessing the vigor of emerging and developing countries that not only enjoy the benefit of digital innovation simultaneous to countries with advanced economies but also demonstrates leapfrogging accomplishment in the IoT society should be considered as a promising solution to the former option.

\subsubsection{Neo Open Innovation by Harnessing Soft Innovation Resources}

Confronting the foregoing dilemma between $R \& D$ expansion and marginal productivity of ICT decline, HRIFs have been endeavoring to transform into a new business model that creates suprafunctionality by harnessing the vigor of soft innovation resources that arouse and activate latent self-propagating function as demonstrated in Fig. 13. 
International Journal of Managing Information Technology (IJMIT) Vol.10, No.4, November 2018

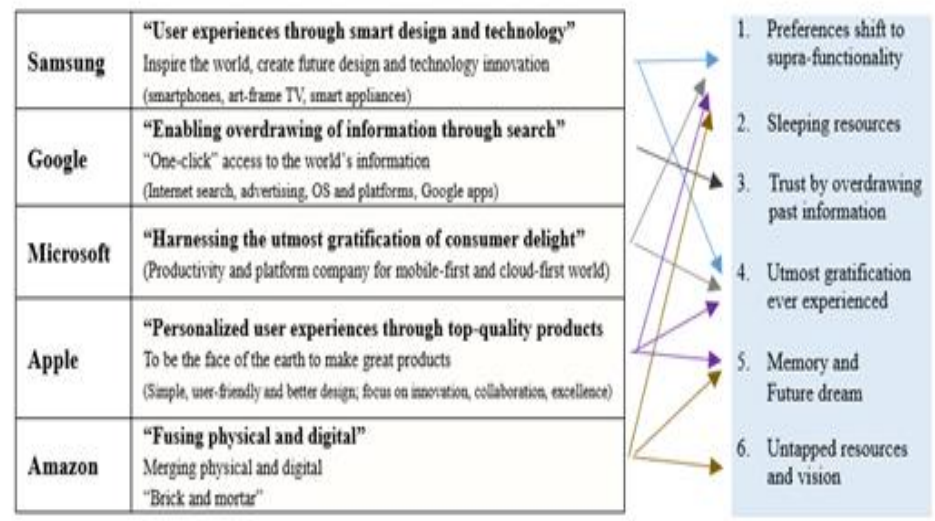

Figure 13. Transformative direction of HRIFs against productivity decline in the digital economy.

Neo open innovation that harnesses the vigor of such soft innovation resources as demonstrated in Fig. 14 could be a promising solution to the latter option (option (ii) in 2.2).

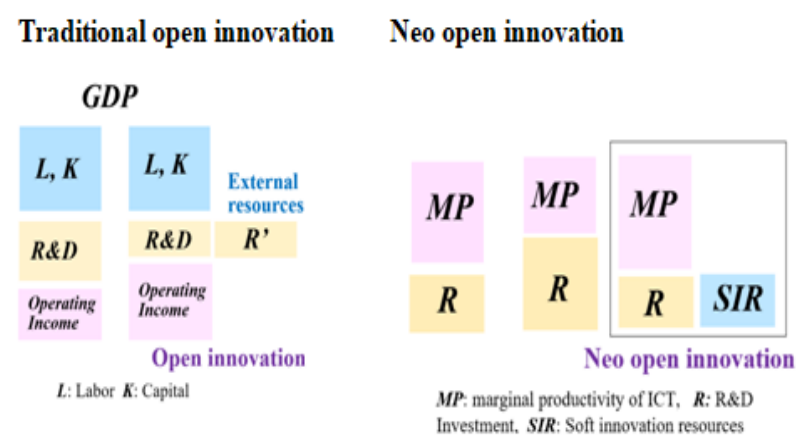

Figure 14. Concept of neo open innovation.

\section{Central Role of Soft InNovation Resources}

\subsection{Conceptualization And Operationalization OF Soft Innovation RESOURCES}

\subsubsection{Three Approaches for Conceptualization and Operationalization}

Based on the augmented permeation of the Internet into broad ICT and subsequent creation of new social ecosystem particularly with smartphone as reviewed in Section 2, innovation dynamism in the IoT society that has been activated by soft innovation resources can be described as follows:

(i) Since global ICT firms are at the forefront of the IoT society, soft innovation resources, their critical resources against productivity decline in the digital economy, seem to be a condensate or crystal of the Internet/smart phone.

(ii) Soft innovation resources arouse and activate a latent self-propagating function indigenous to ICT which can be attributed to the Internet permeating into soft innovation resources.

(iii) The activated self-propagating function induces functionality development which leads to 
International Journal of Managing Information Technology (IJMIT) Vol.10, No.4, November 2018

supra-functionality beyond economic value corresponding to a shift in people's preferences. This shift in turn induces further advancement of the Internet.

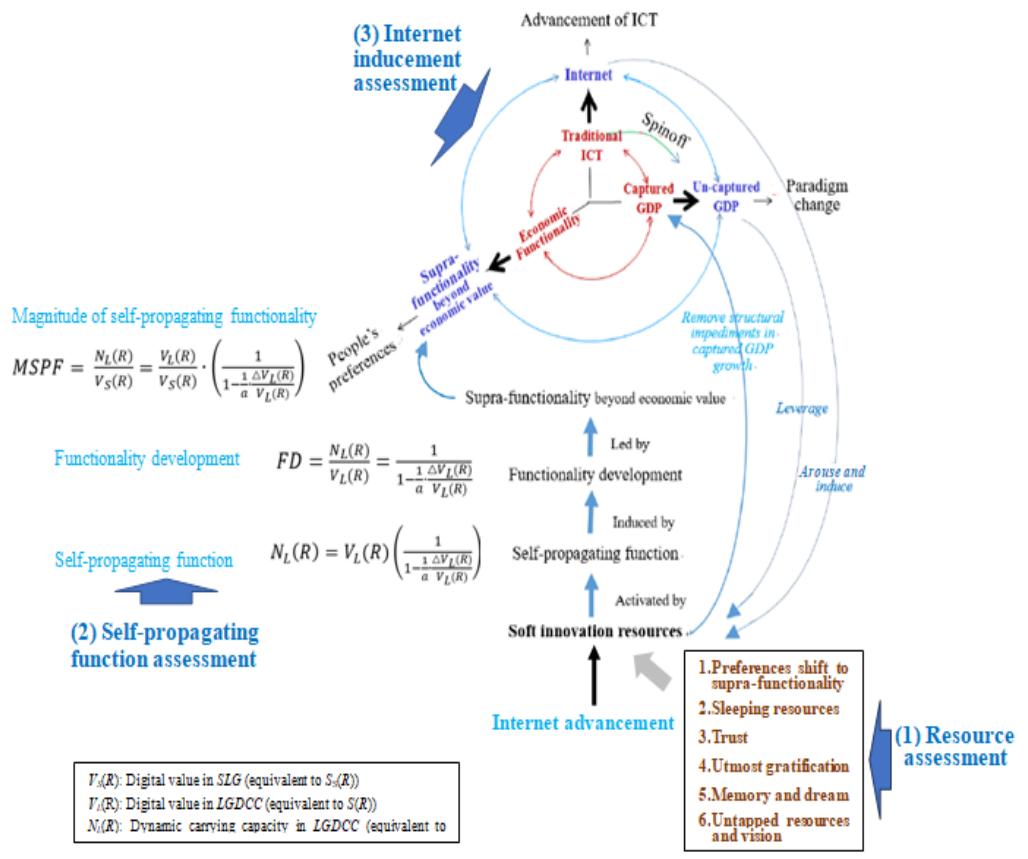

Figure 15. Three approaches for conceptualization and operationalization of soft innovation resources

\subsubsection{Assessment of Soft Innovation Resources as a Crystal of the Internet}

Assessment of soft innovation resources can be attempted by the three approaches as illustrated in Fig. 15 corresponding to the above three postulates.

\section{1) Resources Assessment}

First, taking typical soft innovation resources, correlation with the advancement of the Internet/ smartphone was examined.

\section{2) Sleeping Resources}

Following the preceding analysis on "Uber's Ride-sharing Revolution" [24], effect of the advancement of the Internet on Uber increase was examined. Given the close relationship between the Internet and smartphone dependence as demonstrated in 2.1.1, monthly trend in smartphone dependence was used. Result of analysis is summarized in Table 2 which is statistically significant and demonstrates that the advancement of the Internet (via smartphone) significantly contributed to utilization of sleeping resources by reducing prices typically observed in Uber.

Table 2. Correlation between smart phone and Uber in New York (Jun. 2013 - Sep. 2015).

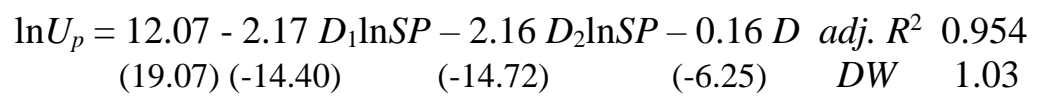
(19.07) (-14.40)
$(-6.25)$

$U_{p}$ : Price of Uber (US\$/trip); SP: Smartphone share in the US telephone market (\%).

$D$ : Dummy variables; $D_{1}$ : Jun. 2013 - Oct. $2014=1$, others $=0 ; D_{2}$ : Nov. 2014 - Sep. $2015=1$, others $=0 ; D$ : Jun. 2015 - Sep. $2015=1$. others $=0$. 
International Journal of Managing Information Technology (IJMIT) Vol.10, No.4, November 2018

The figures in parentheses indicate the t-statistics: all are significant at the $1 \%$ level except ${ }^{*} 5 \%,{ }^{* *} 10 \%$ (same as following analyses).

\section{3) Trust}

Following the preceding analysis on "Co-evolution between trust in teachers and higher education toward digital-rich learning environments" [25], effects of the advancement of the Internet on trust increase were examined. Result of the analysis is summarized in Table $\mathbf{3}$ which is statistically significant and demonstrates that the advancement of the Internet contributed to trust increase in ICT advanced 12 countries.

Table 3. Correlation between Internet Dependence and Trust in 20 countries (2013).

$$
\begin{aligned}
& \ln X=2.59+0.32 D_{1} \ln I D-0.18 D_{2} \ln I D-2.14 D_{1}-0.16 D_{\alpha}+0.10 D_{\beta} \text { adj. } R^{2} 0.734 \\
& \begin{array}{lllll}
(4.94) & (1.96)^{*} & (-1.35)^{* *} & (-2.20)^{*} & (-5.25)
\end{array}
\end{aligned}
$$

$X$ : Level of trust in teachers to deliver a good education; $I D$ : Internet dependence; $D$ : Dummy variables

$D_{1}$ : Israel, Czech, Singapore, France, New Zealand, Germany, Korea, Switzerland, Japan, UK, Finland, Netherland $=1$, others $=0$

$D_{2}$ : China, Turkey, Brazil, Italy, Greese, Portugal, USA, Spain $=1$, others $=0$

$D_{\alpha}$ : Korea, Japan $=1$. others $=0 D_{\beta}:$ USA, Spain $=1$, others $=0$

\section{4) Memory and Dream}

Following the preceding analysis on "Co-evolution between streaming and live music" [26], effect of the advancement of the Internet on reactivation of live music was examined. Similar to Uber, monthly trend in smartphone dependence was used. Result of the analysis is summarized in Table 4 which is statistically significant and demonstrates that the advancement of the Internet (via smartphone) significantly contributed to reactivation of live music.

Table 4. Correlation between Smartphone and Live Music in the US (Jun. 2013 - Sep. 2015).

$$
\begin{aligned}
& \ln L M=1.34+1.13 \ln S P-0.02 D_{1}+0.02 D_{2} \quad \text { adj. } R^{2} 0.996 \\
& \begin{array}{lllll}
\text { (21.67) (77.85) (-2.46) (4.09) } & D W & 1.25
\end{array}
\end{aligned}
$$

LM: Revenue of live music (mil. US\$); SP: Smartphone share in the US telephone market (\%). $D$ : Dummy variables; $D_{1}:$ Feb. $2014=1$, others $=0 ; D_{2}:$ Sep. 2014 - Nov. $2014=1$, others $=0$

\section{5) Untapped Resources}

Following the preceding analysis on "Harnessing women's potential as untapped resources" [21], effects of the advancement of the Internet on untapped resources utilization were examined. Result of the analysis is summarized in Table $\mathbf{5}$ which is statistically significant and demonstrates that the advancement of the Internet contributed to gender balance improvement.

Table 5. Correlation between Internet Dependence, Gender Balance Improvement and Male-dominated Society in 44 Countries (2013).

$$
\begin{aligned}
& \ln Y=0.99+0.30 D_{1} \ln I D+0.40 D_{2} \ln I D+0.36 D_{3} \ln I D \\
& (1.46)^{* *}(1.63)^{* * *} \quad(2.63) \quad \text { (2.16) } \\
& -0.31 D_{2} \ln W-2.93 D_{3} \ln W-0.98 D_{a}+0.72 D_{b} \quad \text { adj. } R^{2} 0.801 \\
& \begin{array}{llll}
(-2.60) & (-5.58) \quad(-7.57) \quad(3.12)
\end{array}
\end{aligned}
$$

$Y$ : Gender balance index; ID: Internet dependence; $W$ : Intensity of male dominated society. 
International Journal of Managing Information Technology (IJMIT) Vol.10, No.4, November 2018

$D_{1}, D_{2}$ and $D_{3}$ : Coefficient dummy variables corresponding to $E M C$ (13 emerging countries), INC(27 industrialized countries) and $C S C$ (4 countries with specific culture), respectively.

$D$ : Dummy variable: $D_{a}$ : BEL, CHL, HUN, TWN, RUS, PRT, BRA, GRC, EGY $=1$, others $=0 ; D_{b}$ : NOR, SAU $=1$, others $=0$.

All cases demonstrate that soft innovation resources have been governed significantly by the advancement of the Internet and are considered as a condensate or crystal of the Internet.

\section{6) Self-propagating Function Assessment}

Next, the second postulate that "attributed to the advancement of the Internet soft innovation resources activate a latent self-propagating function" was examined. Table 6 summarizes the result of the correlation analysis between Internet dependence and self-propagating function in UPM (world circular economy leader). The result is statistically significant and demonstrates that the advancement of the Internet contributed to increase self-propagating function significantly. Its contribution increased as Internet dependence increased.

Table 6. Correlation between Internet Dependence and Self-propagating Function (1995-2017).

$\ln N_{L}(R)=2.973+0.362 D_{1} \ln I D+0.424 D_{2} \ln I D+0.536 D_{3} \ln I D \quad \operatorname{adj.} R^{2} 0.985$

(109.79) (11.30)

(21.51)

DW 1.20

$N_{L}(R)$ : Self-propagating function; $I D$ : Internet dependence; $D$ : Dummy variables

$D_{1:} 1995-2002=1$, others $=0 ; D_{2}: 2003-2007=1$, others $=0 ; D_{3}: 2008-2017=1$, others $=0$

\section{7) Internet Inducement Assessment}

Third, inspired by the preceding two demonstrations, the third postulate that "activated selfpropagating function induces functionality development leading to supra-functionality which in turn induces further advancement of the Internet" was examined.

Table 7 summarizes the correlation between supra-functionality and advancement of the Internet in Japan (which is sensitive to institutional innovation against external shocks and crises).

Table 7. Correlation between preferences shift and the advancement of the Internet in Japan (1994-2012).

$$
\begin{aligned}
& \ln J=-34.77+8.81 D_{1} \ln Q+9.34 D_{2} \ln Q+9.50 D_{3} \ln Q-1.11 D \quad \text { adj.R } R^{2} 0.937 \\
& \text { (-2.97) (3.05) }
\end{aligned}
$$

$J$ : Internet dependence; $Q$ : Preference ratio of supra-functionality beyond economic value;

$D$ : Dummy variables $\left(D_{1}: 1994-1996=1\right.$, others $=0 ; D_{2}: 1997-2003=1$, others $=0 ; D_{3}: 2004-2012=1$, others $=0 ; D: 1994=1$, others $=0)$.

Table 7 shows statistically significant and demonstrates that people's preferences shift to supra functionality beyond economic value significantly induced the advancement of the Internet in Japan. This inducement increased as Internet dependence increased.

All three analyses demonstrate the significant correlation between the advancement of the Internet and soft innovation resources or their subsequent such as self-propagating function and also people's preferences shift to supra-functionality beyond economic value.

These results support the supposition that soft innovation resources could be considered a condensate or crystal of the advancement of the Internet. 
International Journal of Managing Information Technology (IJMIT) Vol.10, No.4, November 2018

Given the co-evolution between these factors in emerging innovation in the digital economy as illustrated in Figs. 11 and 14, it is thus postulated that effective utilization of soft innovation resources would be critical for sustainable growth amidst mega competition in the digital economy.

\subsection{IDENTIFICATION, EXPLORATION AND UTILIZATION OF SOFT INNOVATION RESOURCES}

\subsubsection{Assimilation Capacity}

Since effective utilization of such external resources depends on capacity to assimilate them [19], assimilation capacity has become critical competitive power [16].

The dynamism in creating this capacity can be conceptualized as follows:

(i) Cumulative learning cultivates the capacity of distinguishing valuable soft innovation resources by assessing and selecting them into $(a)$ should take, $(b)$ should not take, and $(c)$ cannot take.

(ii) This distinguishing capacity leads to absorptive capacity to be able to treat accepted soft innovation resources homogeneous to its own innovation stock.

(iii) Through co-evolutionary exercise of absorption assimilation capacity can be developed thereby able to embody absorbed soft innovation to whole value chain of production, diffusion, and consumption.

\subsubsection{Lessons from Amazon}

Amazon's conspicuous accomplishment in jumping into world R\&D leader in 2017 (Fig. 2) can largely be attributed to its noting assimilation capacity.

Starting from an online book-store in 1994 it has been endeavoring to construct growing empire [27] by continuing to transform its business into digital leaders [28].

Through this process Amazon has fully enjoyed effects of network externality and big data treatment in a co-evolutional manner, thereby it has succeeded in developing capacity to identifying, exploring and utilizing innovation resources spilling over from external business environment [29]. This capacity has enabled Amazon to assimilate soft innovation resources by constructing neo open innovation. This assimilation has led Amazon digital leader which in turn enabled it further advancement of its business identity and scope leading to a virtuous cycle between them. Based on this virtuous cycle, it has been endeavoring to develop world leading critical technology that may explore next generational frontier by investing every possible human and financial resources in a top priority basis. Noteworthy is all these efforts have functioned co-evolutional way without which identification of soft innovation resources would not be enabled. Its conspicuous R\&D jumping up to the world top in 2017 as reviewed in Fig. 2 can be attributed to this dynamism.

Amazon insists the concept of R\&D in the digital economy by identifying its scope and content of R\&D as follows [30]:

Technology and content costs include payroll and related expenses for employees involved in the R\&D of new and existing products and services, development, design, and maintenance of the 
International Journal of Managing Information Technology (IJMIT) Vol.10, No.4, November 2018

websites, curation and display of products and services made available on the websites, and infrastructure costs. Infrastructure costs include servers, networking equipment, and data center related depreciation, rent, utilities, and other expenses necessary to support AWS (Amazon Web Services), as well as these and other efforts. Collectively, these costs reflect the investments Amazon make in order to offer a wide variety of products and services to its customers.(It does not include routine or periodic alterations to existing products, production lines, manufacturing processes, and other on-going operations even though those alterations may represent improvements and it does not include market research or market testing activities).

In response to the SEC's (Securities and Exchange Commission) inquiry, Amazon stresses the seamless nature of its R\&D as follows [5]:

Amazon's business model encourages the simultaneous research, design, development, and maintenance of both new and existing products and services. Its teams are constantly working to build new Alexa skills and simultaneously maintain current skills, and these activities are within a continuum of research activities and are not easily distinguishable operationally.

Amazon does not manage its business by separating activities of the type from other activities that are directed at ongoing innovation and enhancements to its innovations. Instead, Amazon manage the total investment in its employees and infrastructure across all its product and service offerings, rather than viewing it as related to a particular product or service; Amazon views and manages these costs collectively as investments being made on behalf of its customers in order to improve the customer experience. Amazon believes this approach to managing its business is different from the concept of planned and focused projects with specific objectives that was contemplated when the accounting standards for $\mathrm{R} \& \mathrm{D}$ were developed.

Given the significant breadth of projects and improvements that Amazon has underway, its employees routinely work concurrently on multiple projects, including projects that could be defined as $R \& D$ in nature and also more routine, ongoing activities to refine, enrich, or otherwise improve or adapt its existing products and services. Similarly, Amazon's activities may focus on developing new products and services, but these activities often result, in whole or in part, in enhancements to existing products and services.

This suggests Amazon's remarkable assimilation capacity that enables it effective utilization of soft innovation resources for overcoming a dilemma between $R \& D$ and productivity decline.

\subsection{Central Role of Soft InNovation Resources}

Authors in their preceding work demonstrated the hybrid role of soft innovation resources that substitutes for gross service capital centered on R\&D and then spills over to gross tangible capital and removes structural impediments in growth [16]. Thereby they demonstrated structure of Finland's recent resurgence and inspired co-evolution between resilience of high-level of welfare/happiness and sustainable growth which previously considered generally trade-off as reviewed in earlier (see Fig. 10). 
International Journal of Managing Information Technology (IJMIT) Vol.10, No.4, November 2018

\section{Conclusion}

In light of a critical dilemma between $R \& D$ expansion and productivity decline that global ICT leaders have been confronting due to a two-faced nature of ICT, dynamism resulting in such dilemma and countermeasures against it were analyzed.

On the basis of an empirical analysis focusing on forefront endeavors to this dilemma by global ICT leaders, their transformative direction into disruptive business model was investigated.

Noteworthy findings include:

(i) Transformation into disruptive business model that creates supra-functionality beyond economic value satisfying people's preferences shift would be a key direction.

(ii) For that, arousing and activating self-propagating function indigenous to ICT and induces new functionality plays a decisive role.

(iii) Soft innovation resources play a significant role in such arousing and activation.

(iv) Neo open innovation that harnesses soft innovation resources can be a solution to this critical question.

(v) It depends largely on assimilation capacities which identify, explore and utilize soft innovation resources and then absorb and assimilate them into whole value chain of production, diffusion and consumption.

(vi) Amazon's conspicuous accomplishment jumping up to world R\&D leader can be attributed to its sophisticated assimilation capacity.

These findings give rise to the following insightful suggestions for sustainable growth in the digital economy which incorporates a two-faced nature:

(i) Neo open innovation should be sought in a priority basis.

(ii) Development of assimilation capacity should be endeavored.

(iii) In this context, Amazon's conspicuous jump up to world R\&D leader should be further analyzed.

(iv) Simultaneous dissemination nature of ICT should be realized.

(v) Efforts in harnessing the vigor of emerging and developing economies should be sought.

This analysis provides new insights for shedding light on exploring a practical solution to a dilemma between R\&D expansion and productivity decline in the digital economy.

Future works should focus on further elucidation of success sources of neo open innovation. Coevolution between harnessing the vigor of both emerging and developing economies and soft innovation resources should be also sought.

\section{ACKNOWLEDGEMENTS}

The research leading to these results is the part of a project: Platform Value Now: Value capturing in the fast emerging platform ecosystems, supported by the Strategic Research Council at the Academy of Finland [grant number 293446]. 
International Journal of Managing Information Technology (IJMIT) Vol.10, No.4, November 2018

\section{REFERENCES}

[1] Tapscott, D., 1994. The Digital Economy: Promise and Peril in the Age of Networked Intelligence. McGraw-Hill, New York.

[2] Department of Broadband, Communications and the Digital Economy (DBCDE), 2009. Digital Economy Future Directions. DBCDE, Camberra.

[3] Watanabe, C., Naveed, K., Zhao, W., 2015a. New Paradigm of ICT Productivity: Increasing Role of Un-captured GDP and Growing Anger of Consumers. Technology in Society41, 21-44.

[4] Bloomberg, 2017. 2017 Global Innovation 1000 Study. Bloomberg, New York.

[5] Fox, J., 2018. Amazon, the Biggest R\&D Spender, Does Not Believe in R\&D, Bloomberg Opinion, 13 April 2018.https://www.bloomberg.com/view/articles/2018-04-12/amazon-doesn-t-believe-inresearch-and-development-spending (retrieved 22.09.2018).

[6] Chesbrough, H., 2006. Open Innovation: The New Imperative for Creating and Profiting from Technology. Harvard Business School Publishing Corporation, Massachusetts.

[7] Watanabe, C., Shin, J.H., Heikkinen, J., Zhao, W. and Griffy-Brown, C., 2011. New Functionality Development through Follower Substitution for a Leader in Open Innovation. Technological Forecasting and Social Change 78 (1), 116-131.

[8] Prahalad, C.K., 2004. The Fortune at the Bottom of the Pyramid. Watson School of Publishing, Washington, D.C.

[9] OECD, 2016. OECD Observer: The Digital Economy. OECD, Paris.

[10] Pew Research Center, 2016. Smartphone Ownership and Internet Usage Continues to Climb in Emerging Economies. Pew Research Center, Washington, D.C.

[11] Ministry of Internal Affairs and Communication (MIC), 2011. White Paper on Japan's Information and Communication. MIC, Tokyo.

[12] UNESCO, 2015. Countries of All Income Levels Nurturing a Digital Economy. UNESCO Science Report: towards 2030. UNESCO, Paris.

[13] Naveed, K., Watanabe, C. \&Neittaanmäki, P., 2018. The Transformative Direction of Innovation toward an IoT-based Society: Increasing Dependency on Uncaptured GDP in Global ICT Firms. Technology in Society 53, 23-46.

[14] Watanabe, C., Moriya, K., Tou, Y., Neittaanmäki, P., 2018a. Structural Sources of a Productivity Decline in the Digital Economy. International Journal of Managing Information Technology 10 (1), 1 20.

[15] Tou, Y., Moriya, K., Watanabe, C., Ilmola, L. \&Neittaanmäki, P., 2018a. Soft Innovation Resources: Enabler for Reversal in GDP Growth in the Digital Economy. International Journal of Managing Information Technology 10 (3), 9-28.

[16] Tou, Y., Watanabe, C., Ilmola, L. Moriya, K., \&Neittaanmäki, P., 2018b. Hybrid Role of Soft Innovation Resources: Finland's Notable Resurgence in the Digital Economy International Journal of Managing Information Technology 10 (4), in print. 
International Journal of Managing Information Technology (IJMIT) Vol.10, No.4, November 2018

[17] Watanabe, C., Kondo, R., Ouchi, N., Wei, H. and Griffy-Brown, C., 2004. Institutional Elasticity as a Significant Driver of IT Functionality Development. Technological Forecasting and Social Change 71 (7), 723-750.

[18] Schelling, T.C., 1998. Social mechanisms and social dynamics, in Hedstrom, P. and Swedberg, R. eds., Social Mechanisms: An Analytical Approach to Social Theory. Cambridge Univ. Press, Cambridge, $32-43$.

[19] Watanabe, C., 2009. Managing Innovation in Japan: The Role Institutions Play in Helping or Hindering How Companies Develop Technology. Springer, Berlin.

[20] Watanabe, C., Lei, S. and Ouchi, N., 2009. Fusing Indigenous Technology Development and Market Learning for Greater Functionality Development: An Empirical Analysis of the Growth Trajectory of Canon Printers. Technovation, 29 (2), 265-283.

[21] Watanabe, C., Naveed, K. \&Neittaanmäki, P., 2017. ICT-driven Disruptive Innovation Nurtures Uncaptured GDP: Harnessing Woemen's Potential as Untapped Resources. Technology in Society51, $81-101$.

[22] Watanabe, C., Moriya, K., Tou, Y. \&Neittaanmäki, P., 2018b. Consequences of the Digital Economy: Transformation of the Growth Concept. International Journal of Managing Information Technology 10 (2), 21-39.

[23] McDonagh, D., 2008. Satisfying Needs beyond the Functional: The Changing Needs of the Silver Market Consumer. Presented at the International Symposium on the Silver Market Phenomenon Business Opportunities and Responsibilities in the Aging Society, Tokyo, Japan.

[24] Watanabe, C., Naveed, K., Neittaanmäki, P. \&Tou, Y., 2016b. Co-evolution of Three Mega Trends Nature Uncaptured GDP: Uber's Ride-sharing Revolution. Technology in Society 46, 164-185.

[25] Watanabe, C., Naveed, K. \&Neittaanmäki, P., 2016c. Co-evolution between Trust in Teachers and Higher Education toward Digitally-rich Learning Environments. Technology in Society 48, 70-96.

[26] Naveed, K., Watanabe, C., Neittaanmäki, P., 2017. Co-evolution between Streaming and Live Music Leads a Way to the Sustainable Growth of Music Industry: Lessons from the US Experiences. Technology in Society50, 1-19.

[27] Kenney, M., 2013. The Growth and Development of the Internet in the United States. In: Cogut B, Ed. The Global Internet Economy. MIT Press, Massachusetts.

[28] Watanabe, C., Naveed, N. \&Neittaanmäki, P., 2018c. Digital Solution Transform the Forest-based Bioeconomy into a Digital Platform Industry: A Suggestion for a Disruptive Business Model in the Digital Economy. Technology in Society54, 168-188.

[29] Galloway, S., 2017. The Hidden DNA of Amazon, Apple, Facebook, and Google. Penguin Random House LLC, New York.

[30] Amazon, 2017. Annual Report 2016. Amazon, Seattle. https://ir.aboutamazon.com/staticfiles/380785a4-779c-4252-897b-539d3ef70680(retrieved 05.09.2018). 
International Journal of Managing Information Technology (IJMIT) Vol.10, No.4, November 2018

\section{Authors}

Yuji Tou graduated from Tokyo Institute of Technology, Japan, and is currentlyspecially appointed associate professor at Tokyo Institute of Technology, Japan (tou.yuji@gmail.com).

Chihiro Watanabe graduated from the University of Tokyo, Japan, and is currently Professor Emeritus at the Tokyo Institute of Technology, research professor at the University of Jyväskylä, Finland, and a research scholar at the International Institute for Applied Systems Analysis (IIASA). (watanabe.c.pqr@gmail.com).

Kuniko Moriya graduated from Aoyama Gakuin University, Japan, and is currently is currently Director of the Bank of Japan. (kuniko.moriya@boj.or.jp).

Pekka Neittaanmäki graduated from the University of Jyväskylä with a degree in Mathematics. He is currently Professor of the Faculty of Information Technology, University of Jyväskylä, Finland. (pekka.neittaanmaki@jyu.fi). 